\title{
A inclusão de alunos com Transtorno do Espectro Autista (TEA) e orientação psicológica em tempos pandêmicos: suas relações e desafios na educação
}

\section{The relationship between inclusion of students with Autistic Spectrum Disorder (ASD) and psychological orientation during the pandemic period: new challenges in education}

\author{
${ }^{1}$ Rejane Fernandes da Silva Vier rejanevier@hotmail.com \\ ${ }^{1}$ Rosemari Monteiro Castilho Foggiatto Silveira \\ ${ }^{1}$ Moisés Marques Prsybyciem
}

\section{RESUMO}

Este artigo tem o objetivo de investigar as percepções de um grupo sobre as relações entre a inclusão na educação de alunos com Transtorno do Espectro Autista (TEA) e orientação psicológica em aulas online em tempos de pandemia pelo coronavírus (COVID-19). Participaram do estudo duas mães de alunos com TEA, uma psicóloga e duas professoras. A abordagem da pesquisa é qualitativa de natureza exploratória e delineada como estudo de caso. Os dados foram coletados por meio de uma entrevista semiestruturada com as mães e com a psicóloga, bem como a aplicação de um questionário para os professores. Os resultados mostraram que houve uma reinvenção das escolas e das práticas educativas dos professores na pandemia para a inclusão e aprendizagem efetiva desses alunos. Os desafios identificados foram, especialmente a dificuldade de utilização pelos professores das tecnologias, a falta de mediação presencial dos professores no ambiente de aprendizagem, a falta de interesse desses alunos para acompanhar as atividades de maneira online e a dificuldade das famílias em se adaptar à nova rotina. Percebe-se ainda que a participação da família e a atuação da equipe multiprofissional a partir de um trabalho integrado, é primordial para concretização de processos inclusivos de alunos com TEA. Esses resultados contribuem para estimular a reflexão sobre a necessidade de qualificação do espaço escolar, das práticas educativas dos professores e da articulação entre a família, a escola e a orientação psicológica, a fim de atender as demandas específicas dos alunos com TEA na educação, durante a pandemia e pós-pandemia.

Palavras-chave: Inclusão Educacional. Autismo. Pandemia. Orientação Psicológica.

\section{ABSTRACT}

This article aims to investigate the perceptions of a group about the relationship between inclusion on the education of students with Autistic Spectrum Disorder (ASD) and psychological guidance during online classes due to coronavirus disease (COVID-19) global pandemic. This study has counted with the participation of wo mothers of students with ASD, a psychologist and two teachers. The research methodology has been qualitative and exploratory case study. Data were collected through a semi-structured interview with mothers and the psychologist, as well as the application of a questionnaire for the teachers. The main results have shown a reinvention of schools and teachers'educational practices during the pandemic to promote inclusion and effective learning of those students. Some challenges were identified for the inclusion of students with ASD through online classes, especially due to the difficulty of teachers to use technology, lack of teacher mediation in learning environment, lack of interest by those students to do online activities, and also difficulty of families to adapt to the new routine. In addition, it is clear that family participation and the performance of a multi-professional team, based on integrated work, is essential to achieve inclusion of students with ASD. Those results have contributed to stimulate the reflection on the need of qualifying the school space, the teachers' educational practices and the connection among family, school and psychological orientation to find the specific demands of students with ASD in education, during the pandemic and the post-pandemic period. Keywords: Educational Inclusion. Autism. Pandemic. Psychological Orientation. 


\section{INTRODUÇÃO}

O atual cenário mundial caracterizado pela necessidade de isolamento e/ou distanciamento social em decorrência da pandemia pelo coronavírus da Sars-CoV-2 que causa a doença COVID-19 traz um novo desafio para as escolas e professores que, atendendo as orientações da Organização Mundial de Saúde (OMS), cumprem medidas protetivas e buscam a reinvenção pelo desenvolvimento de espaços, processos e práticas educativas na modalidade online.(DIAS; PINTO, 2020).

Não há como falar em educação sem abordar como essa se constitui, isto é, como um processo de construção coletiva, que é influenciado por todos os contextos (científico, cultural, econômico, tecnológico, ambiental, político, ideológico, ético e produtivo) inerentes a sociedade. (KRASILCHIK; MARANDINO, 2007). Contudo, vivenciar a educação em um momento de distanciamento social em que as relações são construídas de uma forma muito diferente do que estamos habituados não é uma tarefa fácil.

É fato que a tarefa de promover a inclusão educacional torna-se ainda mais complexa neste momento de distanciamento e isolamento social, uma vez que deve se tratar da inclusão, partindo das necessidades e especificidades apresentadas pelos alunos e pelos profissionais visando atender as demandas trazidas pelos alunos, familiares, dentre outros de um modo integrado e participativo (UNESCO, 2020).

Apesar dos inúmeros avanços evidenciados na educação e na sociedade que corroboraram para que a pessoa com deficiência venha ocupar seu espaço na sociedade, assim como a implementação de leis que reforçam os diretos do cidadão e direcionam os mecanismos de atendimento às necessidades educacionais especiais dos alunos, muito ainda há que se caminhar para a efetivação da inclusão educacional (FACION, 2008).

Assim, considerado público-alvo da Educação Especial, o aluno com Transtorno do Espectro Autista (TEA) encontra-se cada vez mais inserido (ou, pelo menos deveria) no espaço escolar e nos convida a pensarmos em uma educação de fato inclusiva e que atenda às suas demandas. Silva e Mulick (2009, p. 117) afirmam que:

o transtorno autista (ou autismo infantil) faz parte de um grupo de transtornos do neurodesenvolvimento denominados Transtornos Globais do Desenvolvimento (TGDs), Transtornos Invasivos do Desenvolvimento (TIDs) ou Transtornos do Espectro do Autismo (TEAs).

Pensar uma educação inclusiva para o aluno com o TEA implica na necessidade de o professor conhecer, por exemplo, as suas características. Esse transtorno encontra-se classificado na categoria dos Transtornos Globais do Desenvolvimento (TGD). Para Mecca et al. (2011, p. 116), os TGD são caracterizados pelas "anormalidades qualitativas e abrangentes em três domínios do desenvolvimento: interação social recíproca, comunicação e presença de um repertório comportamental de interesses restritos, repetitivo e estereotipado”.

Conforme os critérios de diagnósticos do Diagnostic and Statistical Manual of Mental Disorders (Manual Diagnóstico e Estatístico de Transtornos Mentais) (DSM- IV-RT) o TEA é caracterizado pelos seguintes critérios descritos a seguir:

- Déficits persistentes na comunicação social e na interação social em múltiplos contextos, conforme manifestado pelo que segue, atualmente ou por história prévia.

- Padrões restritos e repetitivos de comportamento, interesses ou atividades, conforme manifestado por pelo menos dois dos seguintes, atualmente ou por história prévia. 
- Os sintomas devem estar presentes precocemente no período do desenvolvimento (mas podem não se tornar plenamente manifestos até que as demandas sociais excedam as capacidades limitadas ou podem ser mascarados por estratégias aprendidas mais tarde na vida).

- Os sintomas causam prejuízo clinicamente significativo no funcionamento social, profissional ou em outras áreas importantes da vida do indivíduo no presente.

Essas perturbações não são mais bem explicadas por deficiência intelectual (transtorno do desenvolvimento intelectual) ou por atraso global do desenvolvimento. Deficiência intelectual ou transtorno do espectro autista costumam ser comórbidos; para fazer o diagnóstico da comorbidade de transtorno do espectro autista e deficiência intelectual, a comunicação social deve estar abaixo do esperado para o nível geral do desenvolvimento.

Assim sendo, a inclusão educacional do aluno autista é hoje uma prática evidenciada no meio escolar e uma tarefa que envolve não somente a escola, mas a família e os profissionais das diferentes áreas que atuam na intervenção, como os psicólogos. Contudo, atender o aluno com TEA pressupõe um trabalho integrado entre os profissionais e o conhecimento do processo de aprendizagem de cada indivíduo em sua singularidade atendendo as suas necessidades e especificidades (CABRAL; MARIN, 2017).

Enquanto Ciência a Psicologia tem como foco o comportamento humano e traz importantes contribuições para a educação inclusiva, incluindo o TEA. Nessa perspectiva, a prática do profissional psicólogo na intervenção com autistas não está focada apenas nos comportamentos da criança, mas de todos que o cercam (por exemplo, os pais, professores, equipe pedagógica, direção) e que consequentemente encontram-se envolvidos no processo de inclusão, fazendo dessa uma prática possível.

De acordo com Lemos, Salomão e Ramos (2014) a considerar as dificuldades de interação social, comunicação e comportamento enfrentados pelo autista são necessárias estratégias para aquisição de habilidades específicas que contribuam para a melhora nas habilidades sociais desses indivíduos. Todavia, se consideramos o momento de distanciamento e isolamento social, recomendado pela OMS como medida protetiva em tempos pandêmicos devido ao COVID-19, esse desafio exige a reflexão e a busca de ações que otimizem as formas de ensino oferecidas durante a pandemia de modo que essas não favoreçam ou acentuem ainda mais a exclusão, mas sim oportunizem a participação efetiva dos alunos e o acesso a aprendizagem.

Diante do exposto, este estudo tem como objetivo investigar as percepções de um grupo constituído de mães, professores e psicóloga sobre as relações entre inclusão na educação de alunos com TEA e orientação psicológica em aulas na modalidade online em tempos de pandemia pelo coronavírus (COVID-19).

\section{PERCURSO METODOLÓGICO}

Para o desenvolvimento deste estudo optou-se pela abordagem qualitativa de natureza exploratória pelo fato de proporcionar uma maior familiaridade e compreensão do problema. Em relação aos procedimentos a pesquisa foi delineada como estudo de caso. Este tipo de pesquisa consiste em uma investigação mais aprofundada para obtenção de conhecimento de um ou poucos objetos de estudo (GIL, 2010).

Participaram deste estudo exploratório como fonte de informação duas (02) mães de alunos autistas, duas (02) professoras dos alunos e uma (01) psicóloga que atende aos alunos e que atua de forma participativa junto à escola da rede privada de ensino do município de Ponta Grossa, Paraná (Brasil). Para coleta/construção dos dados utilizou-se como instrumento uma entrevista semiestruturada (mães e psicóloga) e aplicação de um questionário (professoras), como se apresenta a seguir no quadro 1. 
Quadro 1 - Questões da entrevista semiestruturada (mães e psicóloga) e do questionário (professores)

\begin{tabular}{|c|c|c|}
\hline \multicolumn{2}{|c|}{ Entrevista semiestruturada } & Ouestionário \\
\hline Mães & Psicóloga & Professores \\
\hline $\begin{array}{l}\text { - Como está sendo ofertado o ensino } \\
\text { para o seu filho durante a pandemia? } \\
\text { - Os conteúdos estão flexibilizados? } \\
\text { - Você acredita que os conteúdos } \\
\text { estão de fato atendendo as } \\
\text { necessidades dos alunos? } \\
\text { - Quais as dificuldades enfrentadas } \\
\text { pelo seu filho em relação ao ensino } \\
\text { neste momento que você percebeu? } \\
\text { - Você percebe aspectos positivos do } \\
\text { trabalho desenvolvido pela escola neste } \\
\text { momento? } \\
\text { - Você apontaria sugestões de formas } \\
\text { diferentes de trabalho neste momento? } \\
\text { Sugira: } \\
\text { - Como sua família tem enfrentado os } \\
\text { obstáculos relacionados a pandemia } \\
\text { neste momento? }\end{array}$ & $\begin{array}{l}\text { - Como você avalia a prática clínica } \\
\text { de intervenção com os autistas em } \\
\text { tempos de pandemia? } \\
\text { - Quais as dificuldades que você } \\
\text { percebe em relação ao momento } \\
\text { vivenciado pelos pacientes e a sua } \\
\text { família? } \\
\text { - Você tem conhecimento do } \\
\text { trabalho desenvolvido pela escola em } \\
\text { tempos de pandemia? Se sim como } \\
\text { avalia esse trabalho? } \\
\text { - Como se dá a relação do } \\
\text { profissional psicólogo com a escola na } \\
\text { tarefa de promover a inclusão? } \\
\text { - Quais as contribuições da } \\
\text { Psicologia e da intervenção com } \\
\text { os alunos autistas em tempos de } \\
\text { pandemia? }\end{array}$ & $\begin{array}{l}\text { - Como está sendo ofertado } \\
\text { ministrado o ensino em sua instituição } \\
\text { durante a pandemia? } \\
\text { - Os conteúdos são flexibilizados? } \\
\text { - Você acredita que os conteúdos } \\
\text { estão de fato atendendo as } \\
\text { necessidades dos alunos? } \\
\text { - Quais as dificuldades enfrentadas } \\
\text { em relação ao ensino especial neste } \\
\text { momento que você percebeu? } \\
\text { - Que aspectos positivos do trabalho } \\
\text { desenvolvido você percebe neste } \\
\text { momento? } \\
\text { - Como tem sido a relação família e } \\
\text { escola neste momento } \\
\text { - Como a escola e você tem } \\
\text { enfrentado os obstáculos relacionados } \\
\text { a pandemia neste momento? }\end{array}$ \\
\hline
\end{tabular}

Fonte: Autoria própria (2020).

Para o desenvolvimento deste estudo, em relação as considerações éticas, os participantes aceitaram participar e assinaram o Termo de Consentimento Livre e Esclarecido (TCLE). Todos os aspectos éticos foram respeitados. Assim, foram garantidas a confidencialidade dos dados coletados/construídos, pois apenas os pesquisadores tinham acesso. Para preservar o anonimato os participantes foram identificados por códigos, as mães (M1 e M2), as professoras (P1 e P2) e psicóloga (PS).

A análise dos dados foi realizada utilizando a metodologia de análise de conteúdo, sendo desenvolvida em três fases conforme Bardin (1991). Para esta autora, as fases constituem a pré-análise; a exploração do material e o tratamento dos dados; e a inferência e a interpretação. Neste processo, emergiram, a posteriori, duas categorias: i) percepções sobre Educação Inclusiva de alunos com TEA em tempos de Pandemia; e ii) reinventando o ensino em tempos pandêmicos: um olhar acerca da Psicologia.

\section{RESULTADOS E DISCUSSÕES}

A inclusão educacional teve significativos avanços no espaço escolar, contudo, essa ainda se constitui como um desafio para professores, alunos e familiares, principalmente em tempos pandêmicos em que o ensino online (remoto) escancara, cada vez mais, a necessidade de qualificação do espaço escolar e das práticas educativas que, geralmente, são excludentes. Diante desse cenário os resultados dessa pesquisa traduzem as percepções dos participantes do referido estudo de caso. Assim, apresenta-se a análise das entrevistas e do questionário respondidos pelos participantes, os quais foram estruturados em duas categorias de análise. 


\section{1 Percepções sobre Educação Inclusiva de alunos com TEA em tempos de Pandemia}

O processo inclusivo de alunos com TEA em relação ao acesso, a permanência e o sucesso de todos no espaço escolar se configuram como um desafio a ser enfrentado por todos os atores sociais envolvidos. Estamos vivenciando um momento muito difícil para a sociedade de um modo geral, em decorrência da pandemia da COVID-19, e atendendo as recomendações da OMS que são fundamentais para prevenção da saúde, a sociedade vive um período de distanciamento e/ou isolamento social que transformou significativamente a rotina das famílias e o cenário educacional no Brasil.

A escola e os professores buscam se reinventar nesse momento para cumprir com os objetivos de uma formação para cidadania, justiça social e inclusão. Assim sendo, nas respostas ao questionamento sobre como o ensino está sendo ofertado nesse momento de pandemia, os participantes relataram que a escola adotou novos mecanismos, como expresso pela professora P1: "aulas online, chats, gravação de aulas (vídeos), gravação de chats, roteiros e gabaritos escritos”. Percebe-se que a escola, aqui em específico, da rede privada de ensino, implementou novas formas de atendimento e acompanhamento dos alunos, por exemplo, as aulas e interação professor-aluno-família na modalidade online.

O que constatamos é que as tecnologias surgiram como aliadas nesse período e que encurtando distancias surgem como um recurso educacional. Conforme Krasilchik e Marandino (2007) não há como imaginar a vida nos dias atuais sem a utilização da ciência e da tecnologia para auxiliar nas atividades escolares, profissionais, lazer, assim como os benefícios de seus recursos. Todavia, há que se refletir também sobre os aspectos negativos relacionados a essas que embora oportunizem o desenvolvimento do trabalho, o lazer entre outros, o uso indevido pode também ser prejudicial as pessoas.

Em relação à educação online (remota), ocasionada pela pandemia, os professores relatam as dificuldades que enfrentaram na utilização das Tecnologias de Informação e Comunicação (TIC), como expresso no relato de P1: "senti dificuldade também em trabalhar com a ferramenta digital, sendo ela a principal ponte nesse momento e não um complemento como era antes”. No entanto, na fala da mesma professora percebe-se que apesar das dificuldades, os professores estão abertos a essa nova forma de ensino, P1 complementa: aprender um novo jeito de ensinar, estudar, percebo um redescobrimento de todos os envolvidos neste momento".

A participante P2 acrescenta que apesar das carências desses mecanismos, entende como único meio neste momento, como expresso em seu relato: "infelizmente devido a situação que estamos vivendo é melhor acontecer dessa forma do que não ter nenhum contato com os conteúdos”.

Esta situação tem exigido uma nova maneira de ensinar dos professores e o apoio das famílias, conforme expressa P1: "para as famílias que estão dando suporte, auxílio e apoio nesse momento, acredito que os conteúdos estão atendendo as necessidades do momento".

Atender a proposta de inclusão numa perspectiva em que seja de fato uma inclusão educacional, na qual os objetivos de ensino sejam atingidos e o aluno seja agente no processo de ensino e aprendizagem ainda é um desafio para as escolas como podemos constatar no relato da professora P1: "o colégio tem oferecido todo suporte necessário. No começo, senti muita dificuldade, principalmente pela falta do contato com as crianças, em especial com os alunos de inclusão, pois eles precisam muito do contato olho a olho”. Tal dificuldade é acentuada se considerarmos as dificuldades decorrentes do quadro dos alunos com TEA e que necessitam de desenvolver a interação no ambiente escolar, o que vai ao encontro das ideias de Lemos, Salomão e Agripino-Ramos (2014), quando dizem que a escola se destaca como um dos espaços mais favoráveis ao desenvolvimento infantil.

Todavia, nesse momento, o desafio vem sendo assumido pelos professores que buscam atender as especificidades dos alunos e aproxima-los para que não se distanciem do ambiente de ensino. Esse fator é corroborado 
na fala de M1: "eu percebo que apesar de ninguém saber qual a melhor forma de trabalhar nesse momento, essas aulas estão dando ocupação para as crianças e não as deixando totalmente longe da escola”. Também a participante M2 chama atenção para as dificuldades:

Sim, com o método online os professores tentam, não e fácil para nenhum lado, é que as professoras também não estão tendo contato com a criança para ver o seu desenvolvimento, mas para as crianças de inclusão é um pouco difícil porque nem todos conseguem ficar em frente ao computador para ver vídeo de explicação da matéria por muito tempo, tem vídeos que são de 15 minutos, deveria ser mais objetivos.

A dificuldade com a nova rotina também é destacada pela professora P1: "dificuldade de adaptação da nova rotina, dificuldades estabelecer uma rotina escolar para as crianças.” Também são apresentadas questões como a dificuldade com a falta de mediação destacada por P2: "muito mais difícil pelo fato de não estar presente no momento das aulas e a falta de mediação nas atividades que não estão acontecendo.”

Os responsáveis também relatam as dificuldades do ensino em atingir as crianças como diz M1: "meus filhos ainda são muito novos para ter um acompanhamento eficaz com esse tipo de ensino!” Para a participante M2: "as atividades que vem adaptadas sim, já os vídeos que vêm são os mesmos dos outros alunos, longos e de material que para a criança não faz sentido porque tem atividades que ele não faz”.

Diante das dificuldades relatadas pelas mães compreendemos a importância da flexibilização das atividades e a adequação de recursos tecnológicos que contemplem as necessidades e especificidades dos alunos com TEA. O simples fato, por exemplo, da flexibilização do tempo de duração dos vídeos a considerar a dificuldades dos alunos em manter a atenção e a utilização de recursos de tecnologia assistiva já contribuem. Consideradas também propulsoras na inclusão educacional de pessoas com deficiência as tecnologias assistivas contribuem também para a ampliação das habilidades e integração da pessoa com deficiência (BERSCH, 2013).

Apesar das dificuldades é visível a forma como a escola busca atender essa demanda como relata a participante P2:

Estamos procurando enfrentar da melhor forma possível, disponibilizando os conteúdos por meio de roteiros e as explicações por videoaula e os esclarecimentos das dúvidas e correções por chat. Videoaulas e chats, muitas vezes, não despertam o interesse dos alunos que necessitam de adaptação curricular.

Há que se ressaltar que essa nova forma de pensar a educação, especialmente a educação inclusiva em tempos pandêmicos ainda consiste em algo muito novo e desafiador e que nos instiga a refletir sobre a prática pedagógica para que a mesma não se torne desconexo ou centrado em técnicas de memorização que não estimulam a compreensão e o desenvolvimento da aprendizagem como sugerem Moscardini e Sigolo (2012, p. 5):

Essa constatação indica que o sucesso do movimento inclusivo depende da reorganização da prática docente, de modo que essas iniciativas incidam sobre todas as variantes que exercem influência sobre a aprendizagem do aluno, impondo uma realidade na qual os professores compreendam esses sujeitos, a partir do potencial que encerram.

Diante do exposto, compreendemos a importância de refletir sobre a inclusão educacional de alunos com TEA como um processo de construção coletiva e que envolve não apenas o contexto escolar, mas o aluno em diferentes aspectos, inclusive o familiar. Assim, na sequência abordamos a reflexão sob a ótica da psicologia, visando, também, refletir as suas contribuições nesse estudo. 


\section{2 Reinventando o ensino em tempos de pandemia: um olhar acerca da Psicologia}

Conforme definição do dicionário Houaiss o termo reinventar significa: tornar a inventar e recriar uma solução para um problema antigo, mas que exige uma nova abordagem, isto é, um constante reelaborar. No momento atual, estamos nos reinventando enquanto seres humanos de um modo geral, recriando soluções para um problema que assola a sociedade hoje, buscando uma nova abordagem para trabalhar com a situação.

Na educação não seria diferente, buscamos uma nova forma de ensinar e aprender. Entretanto, algo que evidenciamos é que além de todas as dificuldades estamos vivenciando um momento de incertezas, riscos e consequentemente de medo pelo novo, momento esse em que as emoções, muitas vezes, conduzem as ações.

As emoções são adaptativas porque preparam, predispõem e orientam comportamentos para experiências positivas ou negativas, mesmo comportamentos de sobrevivência e de reprodução. As emoções fornecem informações sobre a im- portância dos estímulos exteriores e interiores do organismo, e também, sobre as situações-problema onde os indivíduos se encontram envolvidos num determinado contexto (FONSECA, 2016, p. 366).

Os resultados obtidos, neste estudo, traduzem em uma pequena escala os sentimentos de muitos durante essa pandemia como constatamos na fala da participante M1:

Inicialmente foi muito difícil porque o medo se sobressaiu, mas aos poucos o dia-a-dia foi se normalizando dentro das possibilidades. Não digo que está bom, mas é o que temos para o momento. As crianças já entenderam os riscos que podem correr se não permanecerem em casa.

O medo pela nova condição e a necessidade de prevalecer a consciência de que os cuidados são necessários. Não há como negar que os sentimentos e emoções, muitas vezes, confundem-se e são de difícil controle tanto pelos adultos quanto para as crianças, como constatamos na fala da participante PS quando questionada sobre as dificuldades evidenciadas em seu trabalho:

A princípio suspendi os atendimentos no consultório, porém trabalho com uma clientela específica de crianças com TEA e percebi que o distanciamento social estava prejudicando muito o trabalho e as mães também relatavam muitas dificuldades com as crianças o tempo todo somente em casa, sem o convívio escolar. Muitos apresentavam mudanças de comportamento.

A considerar a necessidade de desenvolver aspectos como a comunicação e a interação do indivíduo com autismo a atuação do psicólogo não se resume apenas no desenvolvimento de técnicas ou práticas no contexto clínico. De acordo com os estudos de Benitez e Domeniconi (2018) a inclusão educacional é um processo que envolve a atuação dos diferentes agentes educacionais, entre eles o psicólogo que deve atuar em conjunto com o professor e com a família do aluno com TEA.

Tal relação conjunta de trabalho se faz de suma importância, principalmente nesse momento de distanciamento e isolamento social, o que podemos evidenciar na fala da psicóloga PS quando questionada sobre o trabalho desenvolvido pela escola em tempos de pandemia e a relação entre a psicologia e a escola:

A escola está se reinventando, são utilizados recursos diversificados, embora tenham inúmeras dificuldades, inclusive em desenvolver a flexibilização para os alunos de inclusão, percebo a preocupação com os mesmos. Procuro me inteirar sempre, embora não seja a contento nesse momento, procuro conhecer seus recursos e principalmente manter um diálogo com o intuito de auxiliar nesse processo. 
Outro aspecto apontado pela participante PS é a necessidade de acompanhamento das famílias que buscam contornar a situação nesse momento a considerar que a terapia surge como uma válvula de escape e uma busca por auxílio e suporte emocional.

Ao serem questionadas sobre como as famílias estão enfrentando a situação surgem relatos como da participante M2: “de forma harmoniosa, crianças se adaptaram bem, não ficam sem fazer alguma atividade independente da escola, estão saindo somente para as terapias, a mãe auxilia nessas atividades e o pai trabalhando normalmente em home office". Percebe-se nesse relato que a dinâmica familiar se alterou com a presença dos pais em home office, a participação mais efetiva nas atividades escolares. Uma nova dinâmica no cotidiano das famílias, consequentemente mudanças e com as mudanças também dificuldades para lidar com a situação e que devem ser consideradas como uma dinâmica de enfrentamento tanto para a escola, quanto para as famílias que buscam reinventar-se em tempos de pandemia visando a preservação da saúde tanto física quanto mental.

\section{CONSIDERAÇÕES FINAIS}

É difícil abordar uma reflexão sobre os desafios da inclusão educacional em tempos de pandemia. Isso porque o momento ainda é repleto de dúvidas, riscos, medos e incertezas. A escola e professores hoje, buscam reinventar-se de modo a atender uma demanda que apesar de ser evidenciada pelas escolas há muito tempo consiste ainda em um desafio em tempos considerados normais. Isso porque muito ainda temos a aprender sobre o autisAs famílias experimentando uma nova dinâmica do cotidiano e novos papeis perante a educação dos filhos e procurando desenvolver habilidades de comunicação e interação preenchendo a lacuna do espaço escolar.

Contudo, somadas as dificuldades de enfrentamento desse difícil momento dos indivíduos, que necessitam preservar a vida, e ainda a preocupação com o controle de sentimentos e emoções que podem causar danos à saúde mental.

Os principais desafios e incertezas para inclusão de alunos com TEA por meio das aulas online referem-se a dificuldade de utilização pelos professores das TIC, a falta de mediação presencial dos professores na aprendizagem dos alunos com TEA, a falta de interesse desses alunos para acompanhar as atividades de maneira online e a dificuldade das famílias em se adaptar à nova rotina. Além disso, percebe-se que a participação da família nesse processo é primordial, assim como a atuação da equipe multiprofissional a partir de um trabalho integrado, para real concretização de processos inclusivos de alunos com TEA.

Diante de tais necessidades esse estudo aponta para a urgencia de um trabalho integrado entre a família, a escola e o psicólogo para que juntos possam traçar um melhor caminho para atravessar esse momento e o pós-pandemia.

Estes resultados contribuem, pelo menos em partes, para estimular a reflexão da necessidade de qualificação do espaço escolar, das práticas educativas dos professores e da articulação entre a família-escola-orientação psicológica para atender as demandas dos alunos com TEA na educação. 


\section{REFERÊNCIAS}

AMERICAN PSYCHIATRIC ASSOCIATION. Diagnostic and Statistical Manual of Mental Disorders, Fifth Edition (DSM-V). Arlington, VA: American Psychiatric Association, 2013.

BENITEZ, P.; DOMENICONI, C. Atuação do psicólogo na inclusão escolar de estudantes com autismo e deficiência intelectual. Psicologia Escolar e Educacional, Maringa, v. 22, n. 1, p. 163-172, 2018. Disponível em: $\quad<$ https://www.scielo.br/scielo.php?pid=S1413-85572018000100163\&script=sci_abstract\&tlng=pt $>$. Acesso em: 15 jul. 2020.

BERSCH, R. Introdução a tecnologia assistiva: tecnologia e educação. Porto Alegre (RS), 2013.

CABRAL, C. S.; MARIN, A. H. Inclusão escolar de crianças com transtorno do espectro autista: uma revisão sistemática da literatura. Educação em revista, Belo Horizonte, v. 33, e142079, p. 1-30, 2017. Disponível em: <https:// www.scielo.br/scielo.php?pid=S0102-46982017000100113\&script=sci_abstract\&tlng=pt>. Acesso em: 13 jul. 2020.

DIAS, E.; PINTO, F. C. F. A Educação e a Covid-19. Ensaio: Avaliação e Políticas Públicas em Educação, Rio de Janeiro, v. 28, n. 108, p. 545-554, 2020. Disponível em: < https://www.scielo.br/cielo.php?script=sci_ arttext\&pid=S0104-40362020000300545>. Acesso em: 20 out. 2020.

FACION, J. R. (Org.). Inclusão escolar e suas implicações. 2. ed. Curitiba: IBPEX, 2008.

FONSECA, V. Importância das emoções na aprendizagem: uma abordagem neuropsicopedagógica. Revista Psicopedagogia, São Paulo, v. 33, n. 102, p. 365-384, 2016. Disponível em: <http://pepsic.bvsalud.org/scielo. php?script=sci_arttext\&pid=S0103-84862016000300014 >. Acesso em: 5 jul. 2020.

GIL, A. C. Como elaborar projetos de pesquisa. 5. ed. São Paulo: Atlas, 2010.

KRASILCHIK, M.; MARANDINO, M. Ensino de ciências e cidadania. 2. Ed. São Paulo: Moderna, 2007.

LEMOS, E. L. M. D.; SALOMAO, N. M. R.; AGRIPINO-RAMOS, C. S. Inclusão de crianças autistas: um estudo sobre interações sociais no contexto escolar. Revista Brasileira de Educação Especial, Marília, v. 20, n. 1, p. 117-130, 2014. Disponível em: < https://www.scielo.br/scielo.php?script=sci_ arttext\&pid=S1413-65382014000100009>. Acesso em: 13 jul. 2020.

MECCA, T. P.; BRAVO, R. B.; VELLOSO, R. L.; SCHWARTZMAN, J. S.; BRUNONI, D.; TEIXEIRA, M. C. T. V. Rastreamento de sinais e sintomas de transtornos do espectro do autismo em irmãos. Revista de Psiquiatria do Rio Grande do Sul, v. 33, n. 2, p. 116-120, 2011. Disponível em: <https://www.scielo.br/scielo. php?pid=S0101-81082011000200009\&script=sci_abstract\&tlng=pt>. Acesso em: 22 out. 2020.

MOSCARDINI, S. F.; SIGOLO, S. R. R. L. Inclusão escolar do aluno com deficiência intelectual: práticas pedagógicas no ensino comum e no atendimento educacional especializado. In: ENCONTRO NACIONAL DE DIDÁTICA E PRÁTICAS DE ENSINO, 16., Anais... Campinas: Unicamp, 2012. Disponível em: < http://atividadeparaeducacaoespecial.com/wp-content/uploads/2014/07/INCLUS\%C3\%83O-ESCOLARPR\%C3\%81TICAS-PEDAG\%C3\%93GICAS-NO-ENSINO-REGULAR-E-AEE.pdf >. Acesso em: 28 mar. 2020.

SILVA, M.; MULICK, J. A. Diagnosticando o transtorno autista: aspectos fundamentais e considerações práticas. Psicologia: Ciência e Profissão, Brasília, v. 29, n. 1, p. 116-131, 2009. Disponível em: <https://www. scielo.br/scielo.php?script=sci_arttext\&pid=S1414-98932009000100010>. Acesso em: 13 jun. 2020.

UNESCO. Life in the Times of Covid 19: a guide for parents of children with disabilities. Nova Delhi: 2020. Disponível em: <https://en.unesco.org/ news/another-covid-19-front-line- parents-children-disabilities>. Acesso em: 13 jun. 2020. 